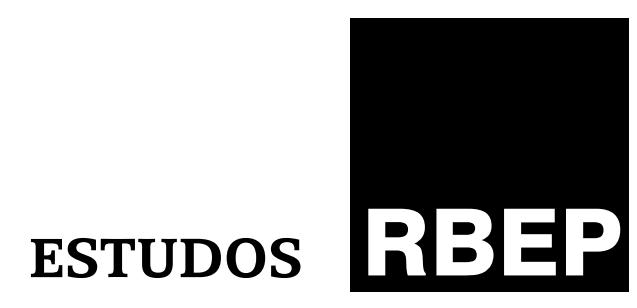

\title{
Práticas e reflexões de professoras numa pesquisa longitudinal
}

Edda Curi

\section{Resumo}

Analisa práticas e reflexões de professoras que participam de um grupo colaborativo no âmbito do Projeto Observatório da Educação, financiado pela Coordenação de Aperfeiçoamento de Pessoal de Nível Superior (Capes). Destaca a constituição do grupo, as ações desenvolvidas, as reflexões das professoras e as considerações que permitem avançar nos processos de ensino de Matemática e formação de professores. Examina cadernos de registros das professoras, atas de memória do grupo e depoimentos e apresenta a análise desse conteúdo, pela perspectiva de Bardin. Conclui ter havido avanços significativos nas práticas, pois o trabalho em grupo favoreceu o processo reflexivo das professoras sobre sua prática e seu desenvolvimento profissional, embora ainda existam fragilidades em algumas reflexões.

Palavras-chave: prática pedagógica; desenvolvimento profissional; grupo colaborativo. 


\section{Abstract \\ Practices and reflections of teachers in longitudinal research}

This article aims to analyze practices and reflections of teachers who takes part in a collaborative group within the Centre for Education Project, financed by the Coordination for the Improvement of Higher Level Personnel (Capes). Also shows group formation; actions taken; teachers' reflections and considerations, which allow an advance of math teaching process and teacher training. In addition, there is an analysis of the teachers' records, group's minutes of memory, statements and analysis of content, from Bardin's perspective. We conclude that there have been significant advances in practices, because the team work facilitated the process of reflection on their practice and professional development, although there are still weaknesses in some reflections.

Keywords: teaching practice, professional development, collaborative group.

\section{Introdução}

Nas últimas décadas, em nosso País, vem se fazendo um esforço muito grande para diminuir as diferenças sociais, mas nossa sociedade ainda é profundamente desigual. Embora várias camadas da população façam esforços significativos que mostram sinais encorajadores no processo de contribuir para a inversão dessas diferenças, isso não é o suficiente.

As disparidades sociais são evidentes na fragmentação do nosso sistema educacional, na falta de aprendizagem, nas dificuldades enfrentadas pelos professores, e só a educação permite melhorar essa desigualdade. O ensino de Matemática faz parte desse contexto. As discussões que estão na mídia nos levam a uma situação de fracasso das crianças na aprendizagem dessa área do conhecimento. No tocante aos professores que ensinam Matemática, percebe-se o empenho na busca de alternativas para a melhoria da aprendizagem dos alunos, no entanto, faltam-lhes oportunidades de contatos com a pesquisa, com as experiências de sucesso, com outros docentes.

A ausência de projetos relativos ao desenvolvimento profissional de professores, às discussões curriculares e à socialização de pesquisas da área tem provocado uma difusão de ideias, às vezes contraditórias, sobre o ensino de Matemática em várias partes do País, além da coexistência de concepções sobre o ensino dessa área do conhecimento nem sempre coerentes e algumas, inclusive, superadas.

Nos últimos anos, houve produção de documentos curriculares, orientações para o ensino, livros e artigos com experiências bem sucedidas de professores. No entanto, essa literatura não tem chegado aos demais 
docentes. A desatualização das bibliografias específicas apresentadas nas ementas dos cursos de Pedagogia é um forte indicador dessa constatação.

Além disso, pesquisas revelam que há outros problemas com relação à formação inicial dos professores dos anos iniciais. Desde a criação do curso Normal no Brasil, ainda no período imperial, não há efetiva presença de disciplinas destinadas ao tratamento dos conhecimentos matemáticos, focando as três vertentes do conhecimento do professor propostas por Shulman (1986), ou seja, conhecimentos matemáticos, conhecimentos didáticos dos conteúdos matemáticos e conhecimentos dos currículos de Matemática. Ainda hoje, há evidências do predomínio da formação generalista nos cursos de formação de professores dos anos iniciais, assentada nos fundamentos da educação, que não considera a necessidade de construir conhecimentos sobre as disciplinas para ensinálas, deixando transparecer uma concepção de que o professor dos anos iniciais do ensino fundamental não precisa "saber Matemática", basta saber como ensiná-la (Curi, 2005).

Outro ponto importante a considerar é que, mesmo com a Lei ${ }^{\circ}$ 9.394/96 (Lei de Diretrizes e Bases da Educação Nacional - LDB), a qual focaliza a importância do estudo dos objetos de ensino na formação inicial, os cursos de Pedagogia em vigor no País destinam uma carga de 36 a 72 horas, do total das 2.880 horas de curso, às disciplinas que envolvem Matemática, ou seja, cerca de $4 \%$ a $5 \%$ da carga horária total do curso (Curi, 2005).

É nesse contexto que um grupo de pesquisa de uma universidade privada da cidade de São Paulo desenvolve, desde o início de 2011, projeto de pesquisa denominado "Prova Brasil de Matemática: revelações e possibilidades de avanços nos saberes de alunos de $4^{\mathrm{a}}$ série $/ 5^{\circ}$ ano e indicativos para formação de professores".

O referido projeto se desenvolve no âmbito do Programa Observatório da Educação financiado pela Coordenação de Aperfeiçoamento de Pessoal de Nível Superior (Capes). Tem como finalidade colaborar para o avanço da pesquisa acadêmica, por meio da análise do banco de dados de Matemática do Sistema de Avaliação da Educação Básica (Saeb) e da Prova Brasil, relativa à $4^{\mathrm{a}}$ série $/ 5^{\circ}$ ano, disponibilizado pelo Instituto Nacional de Estudos e Pesquisas Educacionais Anísio Teixeira (Inep), no Edital 2010, para o Programa Observatório da Educação. Ademais, são finalidades do projeto fortalecer o diálogo entre a comunidade acadêmica, os gestores de políticas educacionais e os diversos atores envolvidos no processo e, ainda, contribuir com elementos para a discussão sobre avaliação educacional, ensino-aprendizagem de Matemática e formação de professores (Curi, 2010).

\section{Objetivos e procedimentos de pesquisa}

Para este artigo, temos o objetivo de apresentar o cenário de estudo, com algumas ações desenvolvidas pela equipe de trabalho, e, a partir 
desse contexto, analisar reflexões realizadas sobre a prática docente em Matemática pelas professoras integrantes do referido grupo de pesquisa, procurando indícios de seu desenvolvimento profissional.

Este artigo é uma síntese da pesquisa que vem sendo realizada. Numa perspectiva metodológica de estudos qualitativos (Creswell, 2007), com base nos resultados do Saeb e nas experiências trazidas pelas professoras, realizamos, em conjunto com elas, análise dos dados das escolas e reflexões sobre o ensino de Matemática e, ainda, elaboramos sequências didáticas que são testadas e seus resultados analisados. Após nova reflexão sobre esses resultados, discutimos propostas de intervenção.

A sequência de atividades é construída coletivamente em momentos de muito diálogo e riqueza na troca entre os participantes. São acordados, após a discussão, os contextos em que as atividades serão desenvolvidas e a ordem de grandeza dos números. Para que a aplicação das atividades seja examinada, as professoras recolhem as produções das crianças, o grupo de pesquisa faz a análise, registra o que lhe chama a atenção e, em seguida, as docentes elaboram um relato reflexivo sobre o desenvolvimento de sua aula e sobre a avaliação das produções de seus alunos, no caderno de registro. Os depoimentos e comentários são registrados nas atas de memória do grupo. Todas as reuniões são gravadas em áudio, e os estudantes de Pedagogia fazem a transcrição dos dados.

O procedimento de pesquisa utilizado neste texto é a análise dos cadernos de registros das professoras, de depoimentos e das atas de memórias do grupo na perspectiva de Bardin (2007).

\section{Contextualizando a pesquisa}

O grupo de pesquisa é constituído, atualmente, por seis bolsistas, alunos do curso de graduação em Pedagogia da universidade; seis professoras da rede pública de São Paulo, que atuam com crianças dos anos iniciais do ensino fundamental; três mestrandos e uma doutoranda, bolsistas; alguns pesquisadores da universidade; e alguns alunos do programa de pós-graduação em Ensino de Ciências e Matemática mestrandos e doutorandos - que participam voluntariamente do projeto.

A partir da base de dados oferecida pelo Inep sobre as aprendizagens matemáticas de alunos de $4^{\mathrm{a}}$ série $/ 5^{\circ}$ ano, reveladas na Prova Brasil, e dos itens de avaliação disponibilizados para a pesquisa, o referido grupo realiza investigações que trazem elementos para a discussão da melhoria da qualidade do ensino de Matemática nos anos iniciais do ensino fundamental e indicativos para a formação de professores.

O grupo se reúne a cada 15 dias na sede da universidade para, partindo da tematização da prática, refletir sobre ela, baseando-se em estudos teóricos que possibilitem avançar na prática pedagógica.

Entre as ações desenvolvidas por esse grupo de pesquisa, destacam-se as que possibilitam ao professor examinar produções escritas de seus alunos e formular hipóteses sobre as dificuldades apresentadas, buscando 
o avanço das aprendizagens e a incorporação dessas análises à sua prática, como contribuição para o desenvolvimento das aprendizagens matemáticas de seus discentes.

Um procedimento comum no grupo é a análise dos dados quantitativos das escolas participantes e, com base neles, cuidar da preparação coletiva de questões discursivas que possibilitem respostas construídas pelos alunos; do desenvolvimento dessas questões em sala de aula; da análise coletiva dos erros e das dificuldades; da reorganização das questões; e da elaboração coletiva de sequências de atividades para o progresso nas aprendizagens dos discentes. Alguns temas matemáticos do currículo dos anos iniciais do ensino fundamental vêm sendo pesquisados por esse grupo, entre eles, o Sistema de Numeração Decimal (SND), o campo aditivo e o campo multiplicativo. Para este texto, comentaremos a pesquisa realizada sobre o ensino e a aprendizagem do SND.

Consideramos que este projeto de pesquisa possa contribuir com propostas de apoio efetivo ao trabalho do professor dos anos iniciais do ensino fundamental, quando ensinam Matemática, com vistas à melhoria da aprendizagem de seus alunos.

\section{Relevância do Programa Observatório da Educação}

A relevância do Programa Observatório da Educação tanto para o ensino como para a pesquisa, no âmbito do qual esta investigação se desenvolve, reside no fato de que ele permite uma pesquisa longitudinal de quatro anos, com o mesmo grupo de professores e escolas; envolve políticas públicas, na medida em que fomenta a análise dos resultados da Prova Brasil das escolas envolvidas; e promove a integração e o diálogo entre elementos de várias instâncias educacionais, durante período de tempo considerável, em que se propõe a realizar um trabalho coletivo.

Outro aspecto a ser considerado é a grande adesão de pesquisadores e alunos do programa de pós-graduação em Ensino de Ciências e Matemática da universidade, sede do projeto de pesquisa.

Os primeiros resultados do estudo vêm sendo apresentados em congressos internacionais - como a Conferência Interamericana de Educação Matemática (Ciaem), o Seminário de Investigação em Educação Matemática (Siem) e o Seminário Internacional de Pesquisa em Educação Matemática (Sipem) - e também veiculados em periódicos da área, dando visibilidade não só à investigação que vem sendo feita, como também ao programa. Os dados referentes a essas publicações serão apresentados em tópico posterior.

Esse movimento vem alimentando tanto nossa produção acadêmica quanto as intervenções nas escolas participantes do projeto de pesquisa e no processo de formação inicial no curso de Pedagogia e de licenciatura em Matemática da universidade. 


\section{Sobre desenvolvimento profissional}

Vários autores, nacionais e internacionais, apresentam reflexões e pesquisas sobre o desenvolvimento profissional de professores. Autores como Fiorentini $(2001,2003,2005)$ e Ponte $(1998,2002)$ consideram o desenvolvimento profissional um movimento contínuo, sem rupturas, que ocorre ao longo da vida. Passos, Nacarato et al. (2006, p. 197), ao realizarem uma meta-análise do conceito de desenvolvimento profissional, consideram que este pode ser entendido como permanente, pessoal, que não tem fim e que envolve muitas etapas e tipos de formação, conforme citação:

Fazendo uma síntese dessas denominações e de suas concepções,
consideramos a formação docente numa perspectiva de formação
contínua e de desenvolvimento profissional, pois pode ser entendida
como um processo pessoal, permanente, contínuo e inconcluso que
envolve múltiplas etapas e instâncias formativas. Além do crescimento
pessoal ao longo da vida, compreende também a formação profissional
(teórico-prática) da formação inicial - voltada para a docência e que
envolve aspectos conceituais, didático pedagógicos e curriculares -e o
desenvolvimento e a atualização da atividade profissional em processos
de formação continuada após a conclusão da licenciatura. A formação
contínua, portanto, é um fenômeno que ocorre ao longo de toda a vida
e que acontece de modo integrado às práticas sociais e às cotidianas
escolares de cada um, ganhando intensidade e relevância em algumas
delas.

Com essas considerações sobre desenvolvimento profissional, podemos dizer que a construção de um grupo de pesquisa, como o citado neste texto, produz laços efetivos entre a escola pública e a universidade, mesmo com as dificuldades decorrentes dos sistemas de ensino.

Consideramos que o grupo de pesquisa em questão propicia um ambiente que favorece o desenvolvimento profissional dos docentes, pois promove discussões sobre a prática entre futuros professores e professores já atuantes (tanto dos anos iniciais do ensino fundamental como dos que atuam como formadores de professores).

Essas considerações estão de acordo com Saraiva e Ponte (2003, p. 28), sobre o desenvolvimento profissional de professores, pois os autores afirmam que, baseados em suas práticas com um grupo de docentes de Matemática em Portugal, o fato de os professores, ao trabalharem em conjunto, exercerem uma reflexão coletiva sobre suas concepções, práticas e conhecimentos acerca da vida profissional proporciona uma estreita ligação com os demais parceiros do grupo.

Consideramos que a visão do processo de desenvolvimento profissional por meio de grupo de estudos entre os professores que ensinam Matemática em diversos graus de ensino potencializa as ações de futuros docentes com seus alunos em sala de aula. 


\section{A constituição do grupo de pesquisa}

Como já foi dito, o grupo de pesquisa envolve atores de vários segmentos educacionais, que se propuseram a realizar um trabalho coletivo. Dessa forma, há no grupo experiências diferenciadas e trajetórias profissionais e acadêmicas diversas, o que pode revelar diferentes fluxos do trabalho coletivo. A esse respeito, Fiorentini (2004) aponta a importância das "diferentes modalidades ou sentidos de trabalho coletivo", destacando "aspectos característicos e constitutivos do trabalho colaborativo", como a "voluntariedade, identidade e espontaneidade" dos seus participantes, a "liderança compartilhada ou corresponsabilidade" e o "apoio e respeito mútuo" que se estabelecem entre eles.

Essa equipe pode ser caracterizada como um grupo colaborativo, pois reúne as características descritas por Fiorentini (2004) para o trabalho e, numa perspectiva de sistematização dos conhecimentos produzidos pela experiência, vem construindo sua identidade, na tentativa de solucionar coletivamente problemas de aprendizagem matemática dos alunos do $5^{\circ}$ ano do ensino fundamental, apontados nos resultados da Prova Brasil de Matemática.

O processo de consolidação da parceria entre os elementos do grupo de pesquisa numa perspectiva colaborativa baseou-se, fundamentalmente, em ouvir a prática das professoras, seus saberes experienciais e suas dificuldades pedagógicas, por meio da reflexividade.

De acordo com Boavida e Ponte (2002), a pesquisa colaborativa constitui uma estratégia, na tentativa de solucionar problemas complexos, difíceis de serem enfrentados individualmente pelos professores. Essa pesquisa colaborativa entre pesquisador(es) e professor(es), segundo Boavida e Ponte, envolve sempre uma negociação que leva a decisões conjuntas, promovendo o diálogo profissional. É de natureza empírica, desenvolvida de forma nem sempre previsível e construída ao mesmo tempo que se desenvolvem relações interpessoais.

Nos primeiros encontros, as professoras, de maneira geral, mostravam-se insatisfeitas com a atual realidade escolar brasileira. Relatavam que os resultados das avaliações externas não lhes eram apresentados, que nem sabiam o que se avaliava e com qual objetivo, além do que não tinham clareza sobre o que e como ensinar as crianças, pois, no Estado de São Paulo, mudanças e adequações curriculares vêm sendo feitas pelas secretarias municipais e estadual de educação nos últimos três anos.

Essa insatisfação foi diminuindo ao longo do trabalho: as professoras mostravam-se ansiosas para iniciar discussões "de sala de aula" - como se referiam a elas - e foram tornando-se mais confiantes e colaborativas à medida que assuntos da prática eram colocados, expondo-se mais e confiando na socialização e nas propostas das colegas e dos pesquisadores.

Os alunos do curso de Pedagogia envolvidos na pesquisa eram muito calados, não participavam das discussões e mostravam pouco interesse nos 
depoimentos das professoras, principalmente quando relatavam situações da escola no geral, sem ater-se às práticas pedagógicas.

Os alunos do curso de mestrado e doutorado mostravam-se arredios e tinham a conviç̧ão de que todas as dificuldades em Matemática dos alunos no ensino médio e superior eram decorrentes da falta de base dos anos iniciais do ensino fundamental e do pouco conhecimento que as professoras que atuam nessa etapa têm da Matemática e do ensino dessa área.

A experiência de constituição desse grupo de pesquisa mostrou-se extremamente satisfatória para seus participantes, que valorizavam os encontros, a troca de experiências, a socialização de ideias, a escuta do outro, o estudo e a construção de novos saberes.

Entendemos que houve a construção de saberes experienciais, segundo a concepção de Fiorentini, Nacarato e Pinto (1999) e Tardif (2002), nos encontros e nas vivências colaborativas: ouvir, falar, analisar a prática pedagógica, compreender e construir novas práticas. A intervenção dos pesquisadores é sempre muito importante na socialização de dificuldades e na análise de questões sobre as práticas, nas sínteses teóricas, na sistematização das aprendizagens, no exercício de uma liderança dialogada.

O professor, na sua prática, constrói conhecimentos que, conforme Fiorentini, Nacarato e Pinto (1999, p. 55), são "saberes experienciais ligados à ação, mesclando aspectos cognitivos, éticos e emocionais ou afetivos", e são, também, dinâmicos e provisórios. Tardif e Borges (2001) destacam que esses saberes articulam iniciativas dos docentes nos contextos próprios e sempre expressam um "saber-fazer" e um "saberser" nas condições da prática.

\section{Primeiras ações desenvolvidas e alguns resultados}

Passamos a detalhar as ações desenvolvidas durante o ano de 2011. A primeira, no período de fevereiro a março, foi estudar informações veiculadas em documentos do Inep sobre Saeb e Prova Brasil. O grupo examinou as respostas dadas por professores, alunos e direção das escolas envolvidas no projeto de pesquisa aos questionários do Saeb.

A análise dos dados das respostas dos professores foi feita por Santos e Pereira (2011), socializada como comunicação científica na $13^{\text {a }}$ Ciaem, realizada em Recife/PE, Brasil, e publicada nos anais do evento. Santos e Pereira destacam, entre as conclusões com base em autores que discutem a formação do professor, como Tardif (2002), que as práticas desses docentes são influenciadas pela formação escolar durante o ensino fundamental, anterior ao curso que os preparou para exercer o magistério. Revelam que os professores relacionam o bom desempenho dos seus alunos em tarefas de Matemática à realização de um trabalho centrado na automatização e na memorização de regras. 
Santos e Pereira (2011) constataram que os professores consideram que estão trabalhando adequadamente e que a formação que dão aos seus alunos será eficaz para que eles concluam o ensino fundamental e o médio e ingressem numa universidade. Os autores ressaltam, ainda, que os professores acreditam que as dificuldades de aprendizagem dos alunos estão relacionadas à falta de interesse e de esforço dos próprios discentes, ao precário acompanhamento dado pela família e à falta de infraestrutura da escola. Concluem expondo que os docentes acreditam que sua carga de trabalho - excessiva - influencie no processo de aprendizagem, pois inviabiliza os procedimentos necessários ao planejamento de aulas a serem ministradas. Outra conclusão foi a constatação de que a maioria dos professores dessas escolas declarou desconhecer os resultados do Saeb.

A nosso ver, as avaliações externas, por exemplo Saeb e Prova Brasil, são importantes apenas porque seus resultados apresentam um panorama de como se encontra o nível de aprendizagem dos alunos e podem ser veiculados, servindo de referência para a elaboração de ações que venham, efetivamente, melhorar o processo de aprendizagem.

A segunda ação desenvolvida pelo grupo de pesquisa foi um estudo dos dados de resultados dos alunos de $4^{\mathrm{a}}$ serie $/ 5^{\circ}$ ano, relativos ao SND, que, particularmente, interessa para este artigo.

Essa parte da pesquisa propiciou a elaboração de alguns artigos que foram apresentados como comunicação científica em congressos regionais, nacionais e internacionais da área ou publicados em periódicos e de duas dissertações de mestrado, uma já defendida em 2012 e outra em fase final.

Atualmente, há duas dissertações em andamento, uma sobre conhecimentos e dificuldades dos alunos de $4^{\mathrm{a}}$ série $/ 5^{\circ}$ ano na resolução de problemas do campo aditivo e outra sobre conhecimentos e dificuldades dos alunos de $4^{\mathrm{a}}$ série $/ 5^{\circ}$ ano na resolução de problemas do campo multiplicativo, e outras duas dissertações que analisam o conhecimento de professores da rede pública de duas cidades sobre os materiais de divulgação da Prova Brasil disponibilizados pelo Inep, uma no Vale do Ribeira em São Paulo e outra no Polo de Camaçari, na Bahia.

\section{Breve síntese dos trabalhos publicados}

O trabalho de Curi (2011) é fruto das primeiras reflexões do grupo de pesquisa sobre esse tema. A autora destaca que o SND, um sistema numérico de uso cotidiano, é pouco compreendido por professores e alunos dos anos iniciais do ensino fundamental. Revela, ainda, que a falta de compreensão das características matemáticas desse sistema de numeração por parte dos professores tem como consequência um ensino mecanizado para seus alunos.

A pesquisa de Curi e Santos (2011b) envolveu dados de uma escola participante do projeto. As autoras destacam que nem as crianças nem 
as professoras estabelecem relações entre o uso social e a organização posicional do SND e que essa situação só pode ser superada se o professor tiver conhecimento matemático do sistema.

O estudo de Rabelo e Curi (2011) analisa os protocolos de 385 alunos, envolvendo seis testes divulgados pelo Inep, abarcando esse tema. As autoras apontam as dificuldades dos discentes quando o número tem zeros intercalados, tanto na identificação da escrita numérica como na decomposição em suas diversas ordens.

O trabalho de Vece, Silva e Curi (2011) examina as resoluções de uma série de questões que envolvem a composição e a decomposição de um número em suas diversas ordens e a identificação de escritas numéricas. As autoras analisaram protocolos de alunos de $4^{\mathrm{a}}$ série $/ 5^{\circ}$ ano de uma das escolas envolvidas no projeto. Entre as conclusões, destacam que os discentes que erraram as questões se apoiam na oralidade, quando decompõem ou compõem um número, e ainda escrevem os números por justaposição, de acordo com a fala, ou seja, 456, por exemplo, é escrito como 400506.

Os dados coletados pelo grupo de pesquisa permitiram a elaboração de artigo de autoria de Curi, Santos e Rabelo, já aprovado, que aguarda publicação em periódico da área. Esse texto apresenta a análise quantitativa e qualitativa de protocolos de 385 alunos em questões que envolvem o SND. Entre os resultados, o trabalho destaca que as características do sistema, como agrupamento de 10 em 10, e o valor posicional de um algarismo no número nem sempre são evidenciados na resolução das tarefas propostas a esses alunos.

A dissertação de Rabelo (2012) - bolsista do Projeto Observatório compatibiliza os dados das seis escolas que dele participam, analisa os testes e as questões abertas sobre o tema em questão, resolvidos por 385 alunos de $4^{\mathrm{a}}$ série $/ 5^{\circ}$ ano das escolas envolvidas, aponta aprendizagens e dificuldades desses alunos com relação a esse tema e destaca que a aprendizagem se limita a números de ordem de grandeza das centenas e que as dificuldades com as características matemáticas do SND são resultantes de um ensino fragmentado e mecanizado, sem envolver a efetiva compreensão do estudante.

Em andamento, com previsão para conclusão no segundo semestre do corrente ano, a dissertação de mestrado de outro bolsista do Projeto Observatório discute o ensino do SND nas turmas de $5^{\circ}$ ano de uma das escolas participantes. Nessa pesquisa, estão sendo analisados documentos oficiais (matrizes curriculares e de avaliação do Saeb), planos de aulas, livros didáticos e cadernos de alunos dessas séries, com o foco no SND, tentando apontar aproximações e divergências entre o que é ensinado e o que é proposto em documentos curriculares e de avaliação.

Após essa apresentação sucinta, passamos ao próximo item relativo às categorias de análise. 


\section{Caracterizando a pesquisa que originou este artigo}

Como já foi dito, a pesquisa é de natureza qualitativa em que o processo se sobressai ao produto.

Para estudo dos dados, recorremos aos princípios de análise de conteúdo em Bardin (2007) e a pesquisas já realizadas no grupo que adotaram esse referencial metodológico. Focamos nos instrumentos que tínhamos disponíveis no decorrer da investigação e no tema "O Ensino do Sistema de Numeração Decimal". As categorias foram construídas a partir da busca de convergências e divergências entre as aprendizagens e as dificuldades dos alunos das escolas envolvidas, entre os textos analisados nos cadernos de registro das professoras, os depoimentos e as atas das reuniões. São elas:

- O Sistema de Numeração Decimal: currículos - prescritos, praticados e avaliados.

- O conhecimento das professoras sobre o Sistema de Numeração Decimal.

- O conhecimento sobre o ensino do Sistema de Numeração Decimal.

- As aprendizagens e as dificuldades dos alunos da $4^{\mathrm{a}}$ série $/ 5^{\circ}$ ano sobre o Sistema de Numeração Decimal.

Os estudos sobre o SND se iniciaram a partir da análise de itens publicados pelo Saeb, com reflexão acerca do que era proposto em documentos curriculares nacionais e locais, do que era ensinado nas escolas e do que efetivamente era proposto na Prova Brasil. Os participantes do grupo de pesquisa resolveram uma sequência de atividades envolvendo o assunto e, com base nas discussões dos resultados, foram feitas as ampliações teóricas sobre o SND.

Após a ampliação dos conhecimentos matemáticos e didáticos do grupo, as professoras passaram a realizar a pesquisa com seus alunos. As questões divulgadas da Prova Brasil foram desenvolvidas com 385 discentes das $4^{\mathrm{a}}$ séries $/ 5^{\circ}$ anos das escolas envolvidas. Os erros e as dificuldades foram analisados pelo grupo de pesquisa e, com base nessas análises, elaboraram-se questões discursivas que foram trabalhadas pelas docentes com seus alunos. Numa segunda etapa, foram analisadas as dificuldades dos discentes nessas questões e, a partir desses achados, o grupo propôs intervenções.

Passamos, a seguir, a apresentar os dados por categoria.

O Sistema de Numeração Decimal: currículos - prescritos, praticados e avaliados

Com base em Sacristán (2000), o grupo fez uma análise dos currículos prescritos, apresentados, moldados, praticados e avaliados no que se refere ao SND. 
A análise pelo grupo de pesquisa de documentos curriculares oficiais - como os Parâmetros Curriculares Nacionais e o documento curricular da Prefeitura Municipal de São Paulo, denominado Orientações Curriculares e Proposição de Expectativas de Aprendizagem, focalizando o ensino de números e do SND - foi de extrema importância. Alguns depoimentos são reveladores:

Achava que no quinto ano bastava uma revisão do SND, pois as crianças já dominavam esse tema, só agora que vi nos documentos curriculares que é preciso não apenas retomar, mas ampliar a ordem de grandeza dos números para que as crianças se apropriem das características desse sistema numérico. (P2, Atas de memória do grupo).

Só agora, analisando o documento da Prefeitura é que percebi que há expectativas de aprendizagem sobre o SND em todos os anos do $1^{\circ}$ ao 5. (P1, Atas de memória do grupo).

As professoras perceberam que os currículos prescritos pelos Parâmetros Curriculares Nacionais e pela Secretaria Municipal de Educação de São Paulo são coerentes no que tange às indicações de conteúdos referentes ao SND. No entanto, tinham dúvidas do significado da frase: compreender e utilizar as regras do SND para leitura, escrita, comparação, ordenação e arredondamento de números naturais de qualquer ordem de grandeza.

Entendo que preciso ensinar as crianças a ler e escrever números naturais, a compará-los e ordená-los, mas não sei se conheço todas as regras do SND e como as utilizo para ensinar meus alunos a ler e escrever os números. Também não sei o que quer dizer qualquer ordem de grandeza. (P4, Atas de memória do grupo).

Consideramos que os documentos se reportam às características do SND como se fossem de domínio dos professores; destacam o uso de números de qualquer ordem de grandeza.

Como fruto de uma reflexão coletiva, o grupo percebeu que os documentos curriculares não exploram quais são as características desse sistema numérico, nem nas prescrições de conteúdo, nem nas orientações didáticas, levando em consideração, talvez, o fato de esse conteúdo ser de uso social e dominado implicitamente pela população. Talvez nenhum participante desse grupo de pesquisa se tivesse dado conta disso até então.

Quanto ao currículo apresentado, Sacristán (2000) considera que ele é elaborado por diferentes instâncias que costumam interpretar e apresentar o significado e os conteúdos do currículo prescrito, com a finalidade de orientar a prática em sala de aula. Em nosso País, o currículo é tradicionalmente apresentado por meio de livros didáticos.

O livro de $4^{\mathrm{a}}$ série $/ 5^{\circ}$ ano utilizado nas escolas participantes era o mesmo e foi analisado também pelo grupo. As professoras perceberam que o livro de $5^{\circ}$ ano propõe poucas atividades com uso do SND, todas com foco de revisão, com números da ordem dos milhões e bilhões, mas sem a 
preocupação de apresentar as características do SND nem de sistematizar as regras desse sistema.

Sacristán (2000) considera, em outra instância, o currículo moldado pelos professores. Ele afirma que, a partir de sua vivência e da cultura profissional, os significados das propostas curriculares prescritas e apresentadas se configuram e são adequados aos alunos pelo professor. No nosso caso, isso acontece por meio dos planos de ensino.

Os planos de ensino das seis escolas foram analisados, e as professoras consideraram que eram muito semelhantes ao currículo prescrito, mesmo sem ser tão coerentes com o currículo apresentado nos livros didáticos utilizados. No entanto, também consideraram que usavam mais os livros didáticos do que o próprio plano de ensino e as atividades que elaboravam e achavam importante para a retomada de coisas que as crianças já deviam saber, mas nas quais ainda tinham dificuldades. É o que Sacristán (2000) chama de currículo em ação.

Para esse autor, o currículo em ação concretiza-se nas tarefas que o professor propõe a seus alunos; nelas é possível verificar o que significam as propostas curriculares para esse professor. Cada tipo de tarefa apresentada reforça as concepções dos docentes em relação ao ensino e à aprendizagem e dá sentido aos conteúdos tratados, destacando o que o professor considera importante para seus alunos.

Quanto ao currículo em ação, praticado até o início do projeto de pesquisa, os depoimentos revelam a influência de um currículo oculto que interfere na prática dos professores, pois estes não se apoiam nos currículos prescritos e moldados por órgãos normativos, nem no apresentado pelo livro didático adotado na escola. As atividades que mais se reproduziam nos cadernos dos alunos eram de cópias de sequências de números em intervalos de 100 em 100, a partir de uma determinada centena, mas explorando, no máximo, o intervalo de 1.900 a 2.000. Outras atividades com números maiores que 1.000 eram bem menos constantes, como a decomposição de números da ordem das unidades de milhar em suas diversas disposições, a colocação de números da ordem das centenas em crescente e decrescente, a identificação de sucessor e antecessor de números da ordem das centenas, a escrita de "números ordinais" em sequências.

Algumas professoras declararam que ainda ensinavam "números romanos" e diferenciavam "números de numerais" em algumas atividades, o que pode revelar a influência do currículo vivenciado por elas enquanto alunas do ensino básico e a falta de discussão curricular na rede pública, embora o currículo de Matemática das redes públicas estaduais e municipal tenha sido modificado recentemente.

O diálogo entre duas professoras, transcrito a seguir, fez parte de uma das reuniões do grupo de pesquisa:

Não se ensina mais "números romanos"? E como os alunos vão ler a horas? (P3, Atas de memória do grupo).

Mas você ensina ler horas em relógio de ponteiros? Eu só ensino no relógio digital, mas não deixo de ensinar os "números romanos." (P5, 
Atas de memória do grupo).

Agora eu é que não entendi: se você não usa para que ensinar? (P3,

Atas de memória do grupo).

Esse diálogo proporcionou um momento muito rico na formação, ou seja, a discussão sobre os critérios de seleção e organização de conteúdos em Matemática e uma visão muito forte dos participantes do grupo de que era preciso ensinar apenas a Matemática prática, que pudesse ser aplicada no dia a dia.

Quanto ao currículo avaliado, o grupo fez dois estudos, um relativo ao que era avaliado pelas professoras e outro, pela Prova Brasil.

Sacristán (2000) refere-se a esse currículo como controle e avaliação do rendimento do aluno, determinando critérios e valorizando algumas atividades em detrimento de outras. Ele considera que pressões exteriores levam a ressaltar, na avaliação, aspectos do currículo ora coerentes, ora incoerentes com os propósitos de quem o prescreveu, de quem o elaborou, ou com os objetivos do próprio professor. Em nosso caso, o currículo é avaliado internamente pelo próprio docente e externamente, por macroavaliações, como a Prova Brasil.

O que verificamos, com base nos dados coletados, é que o currículo avaliado pelas professoras se atém apenas a números da ordem das centenas, com regularidades, e atividades simples de decomposição, escrita do número por extenso e identificação de antecessor e sucessor.

O currículo avaliado na Prova Brasil apresenta, em seus descritores da matriz de avaliação, os mesmos conteúdos e habilidades propostos nos currículos prescritos. No entanto, quando o grupo analisou as questões divulgadas, percebeu que estas apresentavam números da ordem das dezenas de milhares, dos milhões e dos bilhões e, ainda, com zeros intercalados ou na posição final das unidades, o que quebra as regularidades da leitura e da escrita numérica e é um dificultador da aprendizagem. Com essa percepção, o grupo sentiu a necessidade de ampliar seus conhecimentos sobre o SND e o ensino desse tema.

O grupo de pesquisa concluiu que, embora os currículos prescritos, moldados e avaliados externamente tivessem coerência em suas finalidades e objetivos de ensino, o currículo apresentado e o praticado revelavam pontos de discordância, principalmente este último, que não levava em conta os objetivos propostos pelas próprias professoras no planejamento e não se prendia também ao currículo apresentado no livro didático.

O artigo de Vece, Dias e Curi (2011), decorrente da pesquisa que vem sendo realizada, relata que ainda é comum encontrar práticas de ensino baseadas em tarefas por repetição e memorização, em que a leitura e a escrita numérica são aplicadas com a intenção de sistematizar regras sintáticas do sistema, contradizendo as propostas atuais, presentes nos documentos e matrizes curriculares.

Em termos de conclusão, consideramos que não há coerência entre os currículos prescritos, os apresentados pelo livro didático usados na escola 
e os praticados pelas professoras participantes da pesquisa, embora haja coerência entre os currículos prescritos, os moldados pelas professoras e os avaliados externamente. O currículo prescrito e o avaliado têm coerência em seus objetivos e habilidades, porém aquele não aponta caminhos para a efetiva aprendizagem do que é proposto, nem pistas para os trabalhos a serem realizados em sala de aula com a finalidade de fazer uma primeira sistematização desse assunto. Cabe destacar que o uso da decomposição de um número na sua forma polinomial não é mencionado nos currículos prescritos, mas é defendido no currículo avaliado.

Consideramos esse tipo de decomposição inadequado para essa faixa etária, pois envolve a escrita aditiva e multiplicativa do SND com potências de 10, ainda não estudadas pelos alunos. Além disso, as questões propostas na Prova Brasil apresentam elementos dificultadores para sua resolução, como a ordem de grandeza dos números, os zeros intercalados, a decomposição em forma polinomial.

No entanto, ponderamos que os motivos dos baixos índices de aprendizagem sobre esse tema, revelados na Prova Brasil, não são decorrentes apenas dessas incoerências entre o currículo prescrito, o apresentado e o avaliado, pois nos currículos praticados é que estão as grandes lacunas das propostas.

\section{O conhecimento das professoras sobre o Sistema de Numeração Decimal}

Algumas pesquisas, como as de Silva (2009, 2010), já mostravam que professoras dos anos iniciais do ensino fundamental tinham dificuldades com a posicionalidade do SND e com as relações que existem por trás dela para a formação do número. Revelavam ainda que, talvez por suas dificuldades com relação às características desse sistema numérico, as professoras trabalhavam de forma mecânica, "separando os números em casinhas" para efetuar as operações fundamentais.

Com base nessas pesquisas, consideramos importante a realização de atividade diagnóstica, com auxílio da calculadora, para identificar os conhecimentos matemáticos dos participantes do grupo de pesquisa sobre o SND. Havia um combinado que as professoras fizessem as atividades e anotassem seus procedimentos no caderno de registro para posterior análise e socialização. As atividades provocaram discussões e reflexões proveitosas sobre os procedimentos e as respostas encontradas e indicaram pontos frágeis no conhecimento das professoras sobre o SND, além de permitir a retomada de alguns conceitos do sistema, como a base 10, a composição e a decomposição de números, o valor posicional, a composição aditiva e multiplicativa.

Uma das atividades solicitava descobrir dois números consecutivos cujo produto é 210. Foram encontrados protocolos de algumas professoras que mostram competência para resolver situações que exigem conhecimento matemático, mas também foram encontrados outros que revelavam dificuldades em entender o significado da palavra 
"consecutivos". Algumas professoras não tinham a percepção de que uma das características do SND é que um número tem sempre um sucessor cuja diferença entre ele e o imediatamente anterior é 1 e que um número e seu sucessor se denominam consecutivos.

Outra atividade desafiava as professoras a utilizarem um procedimento para resolver a multiplicação 6 x 48 numa calculadora com as teclas 6 e 8 quebradas. Essa tarefa envolve a composição e decomposição de números, e algumas professoras revelaram procedimentos interessantes.

A professora P5 explicou ao grupo os procedimentos que utilizou para realizar a tarefa e mostrou seus conhecimentos sobre propriedades da multiplicação e divisão, ao multiplicar um dos fatores por 2 e dividir o outro também por 2 .

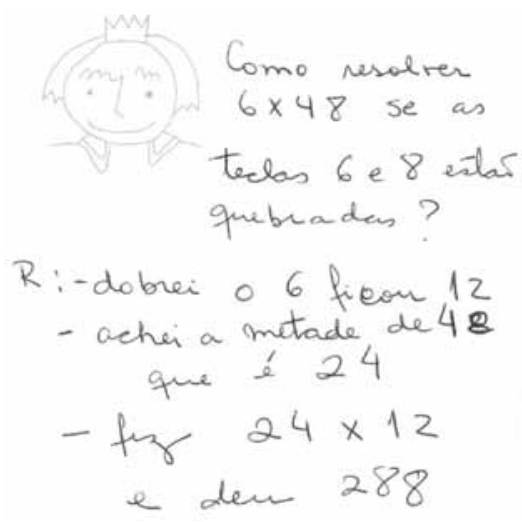

Figura 1 - Protocolo da professora P5

Fonte: Caderno de registro

A professora P2, embora não tenha reunido nos parênteses $(3+3)$ que surgiu da decomposição do número 6 (que era a tecla quebrada da calculadora), explicou seus procedimentos corretamente, tanto no protocolo escrito no caderno de registro como na apresentação às colegas, e também usou noções de dobro e metade.

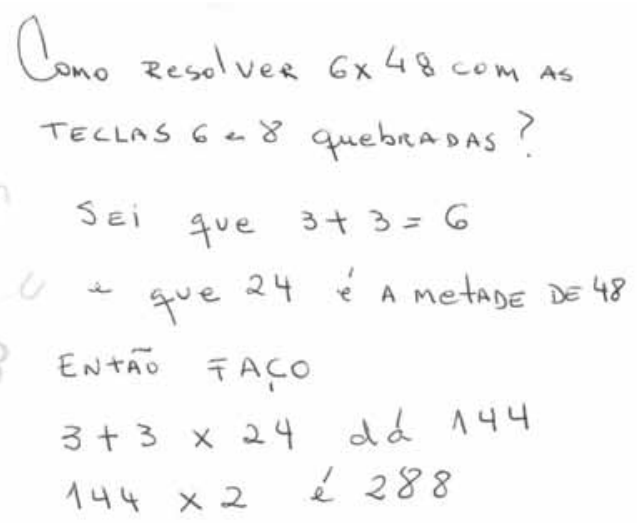

Figura 2 - Protocolo da professora P2

Fonte: Caderno de registro. 
Ao solicitar que as professoras respondessem quantas dezenas tem o número 254, algumas não encontraram a resposta correta, pois, ao que parece, não compreendiam a diferença entre a posição do algarismo "na casa" das dezenas e a quantidade de dezenas que tem o número, ou seja, não têm a noção de posicionalidade do SND. O protocolo da professora P3 exemplifica a situação.

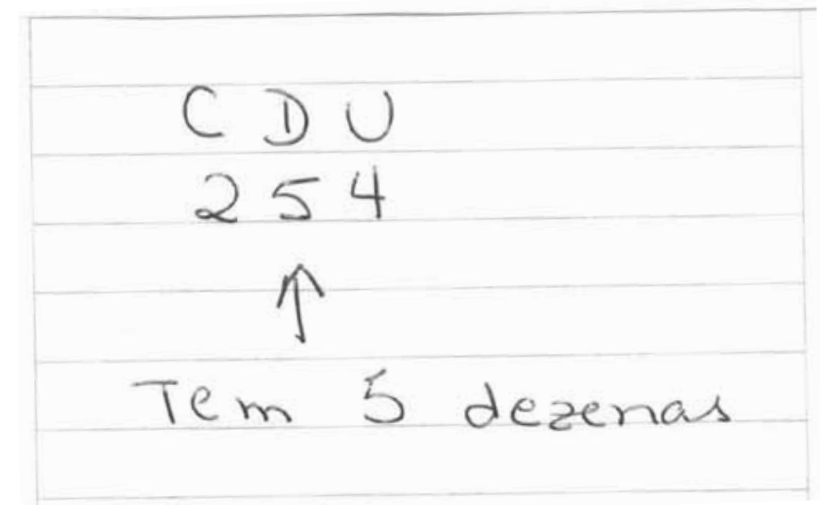

Figura 3 - Protocolo da professora P3

Fonte: Caderno de registros

As indicações das "casas" e a não percepção por parte das professoras de que quando se coloca zero à direita do número ele fica multiplicado por 10 parecem revelar que elas não percebem que o valor de cada algarismo num número é obtido multiplicando-o por uma determinada potência de base 10, outra característica do SND.

Segundo Parra e Saiz (1996), se em um número for colocado um algarismo a mais, necessariamente potências de 10 de "maior grau" que as envolvidas irão intervir em sua decomposição, e o número será dez vezes maior. Como elas afirmam, é uma questão de posicionalidade.

A dificuldade com relação à posicionalidade não era apenas de algumas professoras, estava presente no grupo. Isto é decorrente de o SND ser posicional. Para Parra e Saiz (1996), o SND é mais econômico do que outros sistemas de numeração antigos, em consequência do valor posicional, pois uma quantidade finita de símbolos (no nosso sistema de 0 a 9 , ou seja, dez símbolos) é suficiente para registrar um número de qualquer ordem de grandeza. No entanto, as autoras afirmam que, quanto mais econômico o sistema de numeração, menos transparente ele é, pois oculta ações por trás da posicionalidade para a formação do número, deixando-o econômico.

Essas questões provocaram declarações que mostram a frustração das professoras por não compreenderem adequadamente o SND, embora nem sempre se dessem conta de sua real dificuldade.

A professora P4 revela sua dificuldade com a decomposição e para entender o valor absoluto e o valor posicional dos algarismos nos números. 
Quando não podia usar algumas teclas da calculadora tive dificuldades de realizar a tarefa, pois não consegui "desmontar" o número e também não sabia quantas dezenas tinha o número 254. (P4, Caderno de registro).

A professora P3 revela dificuldades para analisar o valor posicional do número e compreender características básicas do SND - agrupamento de 10 em 10 e troca por elemento de ordem imediatamente superior.

Tive dificuldade para entender o que quer dizer ordens e classes, mas sei colocar os números nas "casinhas" e é assim que ensino meus alunos. (P3, Caderno de registro).

Alguns artigos publicados mostram outros dados da pesquisa, com relação ao conhecimento das professoras quanto ao SND.

Os artigos de Curi (2011) e Curi e Santos (2011a) destacam que a compreensão do SND não era tão simples para as professoras que participavam do grupo de pesquisa, no início de 2011. Revelam ainda que, em função do pouco conhecimento matemático das características básicas do SND, elas faziam um trabalho superficial e mecânico quando ensinavam seus alunos. As autoras concluem que apenas o uso social do SND não oferece condições para o trabalho docente com esse tema (Curi, 2011, Curi; Santos, 2011a).

\section{O conhecimento sobre o ensino do Sistema de Numeração Decimal}

As professoras das escolas analisadas não tinham o hábito de explorar as regularidades de intervalos numéricos, não percebiam a importância de trabalhos orais, de trabalhos com números de ordem de grandeza maiores, nem do uso do livro didático. As atividades propostas por esses livros nem sempre eram realizadas, sendo substituídas por outras mais simples.

Muitas vezes, as docentes declaravam que faziam atividades de decomposição de um número, mas não sabiam o motivo ou mesmo que não achavam importante o aluno saber escrever por extenso um número apresentado em símbolos matemáticos.

As discussões realizadas no grupo de pesquisa incluindo situações concretas de sala de aula, privilegiando a dimensão pedagógica do trabalho do professor, o cotidiano escolar e a perspectiva de que o docente é um pesquisador de sua própria prática, permitiram avanço considerável no grupo. A importância das reuniões se reflete em depoimentos das professoras:

As discussões e os conteúdos tratados no grupo me levaram a outra postura com meus alunos. Procurei observar como respondiam a questão proposta e olhar de perto suas dificuldades. (P6, Atas de memória do grupo)

Não trabalhava quase nada do que foi discutido aqui e achava que meus alunos sabiam tudo do SND e que bastava ensinar as operações. (P1, Atas de memória do grupo). 
Nunca ouvi dizer que os algoritmos da operação podem ser explicados pelas características do SND de agrupamentos de 10 em 10 e trocas para uma unidade superior. Que aprendizagem interessante para minha prática.... (P2, Atas de memória do grupo).

As professoras perceberam que nem sempre a utilização social do SND revela a compreensão das características desse sistema numérico. Elas constatavam a dificuldade dos discentes em compreender o funcionamento de um sistema de numeração usado no cotidiano por todos, mas não sabiam como superar a forma mecânica e fragmentada na abordagem desse assunto com seus alunos.

Uma descoberta nas reuniões do grupo foi perceber a importância de estabelecer relações entre o que as crianças sabem do uso social do sistema numérico e sua organização posicional. A decisão de estudar e analisar a produção e as hipóteses de seus alunos foi uma das temáticas que permearam as discussões do grupo de pesquisa. Concluíram que isso não será fácil, se o professor não tiver conhecimentos matemáticos para ensinar esse conteúdo.

Com a apropriação de conhecimentos matemáticos e didáticos do SND e o estudo sobre as várias instâncias de currículo e análise dos resultados do Saeb/Prova Brasil relativos a questões que envolvem conhecimentos desse sistema, o grupo de pesquisa passou a realizar a investigação com seus alunos a respeito desse tema. Foram elaboradas várias questões envolvendo as características do SND, com a finalidade de os alunos se apropriarem melhor desse sistema numérico. As professoras desenvolveram essas questões com seus alunos: primeiro fizeram uma análise quantitativa dos resultados e depois uma análise qualitativa com o objetivo de identificar aprendizagens e dificuldades com relação a esse tema. Como já foi dito, participaram da pesquisa 385 alunos de $4^{\mathrm{a}}$ série/5º ano das escolas envolvidas no projeto. Os resultados serão discutidos no próximo item.

\section{Aprendizagens e dificuldades reveladas por alunos de $4^{a}$ série $/ 5^{\circ}$ ano em relação ao SND}

As pesquisas realizadas pelas professoras indicam que um percentual significativo - por volta de $80 \%$ - dos alunos de $4^{\mathrm{a}}$ série $/ 5^{\circ}$ ano domina as questões propostas sobre o SND. No entanto, em algumas questões, esse índice de acertos diminui consideravelmente, chegando a cerca de 50\%.

Nossa intenção é focalizar resultados dessas pesquisas, a partir de uma meta-análise qualitativa, visando apontar coerências entre os resultados dos alunos das escolas envolvidas no projeto e produzir novos resultados e sínteses com base no confronto desses estudos.

As análises tomam por base os estudos de Lerner e Sadovsky (1996) a respeito do ensino do SND. Essas autoras consideram o ensino desse tema um problema didático e destacam a posicionalidade do sistema como elemento dificultador. Evidenciam, ainda, que a relação numeração falada/numeração escrita permite que as crianças compreendam a escrita 
numérica com o recurso da sequência oral e a sequência escrita como recurso para compreensão do "nome" do número.

Esses trabalhos revelam, além da posicionalidade do sistema e da escrita baseada na fala, outros dificultadores, como a presença do zero em diferentes posições na escrita numérica, inclusive na posição das unidades; a interferência da oralidade na decomposição de um número com zero intercalado; o tipo de enunciado da questão; o trabalho com as características de agrupamentos e trocas, entre outros. Uma convergência apontada por esses trabalhos foi a dificuldade dos alunos, relativa à decomposição e à composição de números.

Os dados obtidos pelos professores revelam que as dificuldades na decomposição de um número por parte dos alunos podem ser decorrentes da influência sonora na escrita numérica. Discernir as informações ao falar o nome dos números é pertinente e pode ser utilizado na composição dele. Mas, em situações de decomposição do número, esse apoio pode levar a alguns procedimentos desnecessários, como a representação do zero para suprir a ausência de quantidade na classe, por exemplo. Consideramos que esse tipo de apoio serviu como forte interferência nas respostas dos alunos sobre as questões de decomposição numérica, já que muitos apresentaram o seguinte procedimento para decompor o número 8.001 $=8.000+00+01$.

Outra revelação surgiu nas atividades de composição e de decomposição de números. A escrita numérica por justaposição, com base no número falado, ainda era presente entre os alunos que participaram da pesquisa. Na questão que envolve a composição, o percentual de acertos foi menor do que naquelas que implicam a decomposição de um número em suas diversas ordens. Se considerarmos os depoimentos das professoras em relação ao que ensinavam a seus alunos, podemos conjecturar que tarefas que exigem composição de números sejam menos trabalhadas em sala de aula do que as que envolvem decomposição.

Outra convergência entre os resultados das escolas é relativa à ordem de grandeza dos números.

A hipótese levantada pelas professoras é que a ordem de grandeza do número das dezenas de milhar pode ter dificultado o entendimento dos alunos na composição do número natural escrito na forma $10.000+2.000$ +900 + 6. A maioria dos alunos que erraram indicou o resultado 1.296, número da ordem da grandeza de unidade de milhar. O desconhecimento do termo "número natural" pode também ter sido um dificultador na resolução da questão, segundo as professoras.

Os protocolos analisados pelo grupo de pesquisa revelam outra convergência quanto à dificuldade dos alunos com relação aos zeros na escrita numérica. Também a dissertação de Rabelo (2012), decorrente das pesquisas do grupo, mostra que o zero, em qualquer posição, mesmo na ordem das unidades, é um dificultador na composição e na decomposição dos números.

Os relatos das professoras revelam que o zero na escrita numérica não é de uso constante pelos alunos de $4^{\mathrm{a}}$ série $/ 5^{\circ}$ ano e o exemplificam 
com uma tarefa de decomposição do número 1.908. Elas identificam que a maioria dos alunos que erraram a questão fez a decomposição 1.000 $+90+8$.

Outra dificuldade convergente, revelada pelos alunos nos protocolos analisados, é o uso das características do SND. Havia um problema que envolvia uma quantidade de 5.039 envelopes que seriam guardados em caixas com 100 envelopes cada. Os alunos deveriam descobrir quantas caixas seriam necessárias e quantos envelopes sobrariam. Os protocolos dos alunos revelam que eles tentaram fazer a divisão de 5.039 por 100 e não conseguiram encontrar o quociente 50.

Os depoimentos das professoras revelam que o trabalho com agrupamentos e trocas de 10 em 10 e de 100 em 100 não vinha sendo realizado, o que poderia ter dificultado a resolução da atividade que evidenciasse a escrita aditiva e multiplicativa do SND. Esse tipo de resolução revela que as características do SND não haviam sido incorporadas por esses alunos.

No entanto, cabe destacar que as professoras consideram o texto do problema como um elemento dificultador para os alunos, pois, no geral, trabalham atividades que envolvem o SND de forma "descontextualizada".

Alguns protocolos analisados convergem, ao destacar dificuldades das crianças quanto ao enunciado das questões. Os dados mostram que o índice de erros dos alunos foi superior em relação às questões descontextualizadas, independentemente da característica aberta ou fechada do enunciado. A dissertação de Rabelo (2012) também aponta para a maior dificuldade com a resolução de problemas do que com as questões mais diretas com enunciados curtos e diretivos, como "componha" ou "decomponha o número", por exemplo.

Essa consideração mostra a dificuldade existente na mobilização dos conhecimentos matemáticos em situações que podem ser consideradas reais, fora do contexto escolar. A análise dos protocolos dos alunos indica muito mais convergências entre seus resultados do que divergências.

A compreensão do SND não é simples para as crianças que, embora o usem no cotidiano, desconhecem suas características e não exploram as regularidades ou a falta delas. O SND envolve propriedades ocultas e símbolos que permitem escrever todos os números de forma sistemática, e isso não é tão simples de compreender, se não houver um trabalho efetivo na escola.

Voltamos a atentar para nossas observações no sentido da quantidade de algarismos que compõem um número e do trabalho de sala de aula. As análises realizadas por nós mostram que, mesmo descontextualizados, números de menor ordem de grandeza são mais facilmente tratados pelos alunos do que números que envolvem várias ordens de grandeza.

Todos os registros de respostas nos levam a crer que os alunos se apropriaram do tratamento dos números até a primeira ordem da classe das unidades de milhar. Com números dessa ordem de grandeza, os alunos mostram perceber a relação entre a posição e o valor dos algarismos; decompõem e compõem números com base na escrita 
numérica apresentada no texto da questão; e procuram representar a escrita numérica, baseando-se em informações extraídas da fala e do conhecimento prévio a respeito da escrita de números de ordem menor. Além disso, quanto aos itens que apresentam números com zeros intercalados ou na ordem, as unidades tiveram um percentual de erros significativamente maior.

Essa constatação apresentou uma grande contribuição para a prática das professoras envolvidas na pesquisa, contrastando com o pensamento que tinham no início do trabalho, com esse tema a respeito do ensino do sistema. Em geral, elas entendiam que, como a criança de cerca de 10 anos já sabe os números até a unidade de milhar, ela será capaz de generalizar e ler um número de qualquer ordem de grandeza. A constatação de que isso não ocorre derruba, mais uma vez, a concepção linear do processo de aprendizagem da Matemática.

Os resultados dos protocolos analisados nos permitem concluir que, independentemente do conhecimento consolidado na classe das unidades simples, o processo de generalização é construído em espiral, com avanços e retomadas conceituais, sendo ele de inteira responsabilidade do professor. Esse processo se constrói em diferentes âmbitos, que vão formando uma malha a partir da qual as crianças organizam, refletem, reorganizam e ampliam seus conhecimentos a respeito do sistema numérico. Sem a compreensão desse sistema, as crianças não fazem generalizações e utilizam o conhecimento mecanicamente. Essa foi a grande descoberta das professoras participantes da pesquisa.

As constatações reveladas na pesquisa nos permitem afirmar que o ensino do Sistema de Numeração Decimal não é apenas um problema didático, como revelam Lerner e Sadovsky (1996), mas é também um problema de conhecimentos matemáticos necessários para ensinar esse conteúdo; e apenas o uso social desse sistema numérico não é suficiente para permitir ao professor ensiná-lo de forma a torná-lo compreensível para seus alunos.

\section{Considerações finais}

Ao concluir este artigo, destacamos a atuação das professoras tanto no grupo de pesquisa como na sala de aula com seus alunos, a mudança de postura com relação ao ensino e aprendizagem de Matemática. Ela transparece por toda a análise realizada, mesmo quando colocamos o foco nas aprendizagens e dificuldades das crianças; o olhar para seus alunos, para a própria prática e para a postura didática foi impregnando as reuniões do grupo de pesquisa. O relato de uma das professoras ilustra esse fato:

Em primeiro lugar foi preciso vencer barreiras culturais em relação ao ensino de Matemática e isso se deu a partir do momento em que procurei discutir com ajuda do grupo para melhorar minha prática pedagógica. Foi por meio das pesquisas e discussões do grupo que vi uma luz no fim do túnel que levaram a quebrar alguns mitos quanto ao 
uso de instrumentos que podem auxiliar o professor como a calculadora, as cartelas sobrepostas, etc. (P1, Caderno de registro da professora, relatório parcial do projeto).

Podemos afirmar que as investigações realizadas até aqui apontam aspectos importantes no que se refere à aprendizagem e ao ensino do Sistema de Numeração Decimal, contribuindo, certamente, para a formação inicial e continuada de professores que ensinam Matemática. O fato de que é preciso compreender as características matemáticas desse sistema numérico, para poder ensiná-lo, é uma das revelações mais importantes da pesquisa que estamos realizando e aponta caminhos para a formação de professores que ensinam Matemática.

O relato de outra professora é ilustrativo:

\begin{abstract}
Aprendi muitas coisas simples que estavam debaixo de meus olhos, mas que até então não tinha nenhum significado para mim, enquanto professora, como a importância do uso do quadro numérico, o quadro de valor posicional, as cartelas sobrepostas, as atividades envolvendo calculadora para compreensão do SND, o ditado de números, e tantas outras. (P5, Caderno de registro da professora, relatório parcial do projeto).
\end{abstract}

Com relação às professoras envolvidas na pesquisa, destacamos um saber docente construído nas reuniões do grupo, um saber situado na ação coletiva e compartilhada, em que cada participante exerce seu papel, conforme sua experiência profissional, mas todos atuam segundo os objetivos da pesquisa, com a finalidade comum de melhorar a prática. Esse espaço de discussão se constituiu num ambiente de formação em serviço e também de pesquisa e desenvolvimento profissional.

Ao desenvolver as atividades com as crianças percebi os erros mais comuns das crianças e a discussão desses erros no grupo de pesquisa me fez evoluir nas minhas aprendizagens. Nunca havia pensado em olhar o erro dos alunos e pensar nesse registro. Conhecendo o que o aluno sabe fica fácil de intervir e preparar atividades adequadas para sanar suas dificuldades. (P3, Caderno de registro da professora, relatório parcial do projeto).

Consideramos que, em termos de constituição de um grupo de pesquisa colaborativo, este vem se fortalecendo e se consolidando. Como o período destinado à pesquisa é longo, esperamos que o grupo permaneça unido e que não haja desistências de participantes.

É possível concluir que não apenas as professoras, mas o grupo todo está num processo de desenvolvimento profissional. A pesquisa se enriquece pela vivência de situações do cotidiano escolar e contribui para a mudança na prática pedagógica das professoras, para a formação inicial dos alunos do curso de Pedagogia, que, como estão em formação inicial, ainda não têm contato com a prática, e para a renovação dos programas de formação inicial e continuada, em que os pesquisadores da universidade estão envolvidos. 
Consideramos que as reuniões do grupo de pesquisa proporcionaram às professoras a oportunidade de rever sua prática, refletir sobre ela e sobre a aprendizagem de seus alunos. Essa reflexão e essa proximidade com o cotidiano da prática do professor foram fundamentais para a reconstrução do fazer pedagógico, de modo a integrar resultados de pesquisas estudadas à sua realidade de atuação e à melhoria do proceso de ensino e aprendizagem e promover seu desenvolvimento profissional.

Entendemos que pesquisas como estas que desenvolvemos neste projeto abrem espaço para reflexão e, por consequência, ampliam os saberes profissionais de todos os elementos do grupo. Consideramos, ainda, que aproximam a escola pública de ensino básico ao ensino acadêmico, permitindo, aos professores que atuam naquelas escolas, uma reflexão sobre os resultados das pesquisas e sobre as possibilidades de incorporá-las em sua prática; e aos professores acadêmicos, uma reflexão sobre o tipo de pesquisa que vem sendo realizada.

Constatamos, também, que as diversas reuniões realizadas ajudaram a estreitar o relacionamento da rede pública com pesquisadores da universidade. Podemos considerar, assim, que a pesquisa colaborativa, centrada no diálogo e no companheirismo, favoreceu a tomada de decisões para a consolidação de estratégias voltadas à formação continuada de professores, gerando amadurecimento no processo de aprendizagem do grupo, porque possibilita a reflexão dos participantes e o estreitamento das suas relações interpessoais. Embora tenha a desvantagem da imprevisibilidade dos fatos que ocorrem na escola, a pesquisa colaborativa favorece a persistência do professor na busca da melhoria de sua prática, devido às possibilidades de diálogo e reflexão ao longo do tempo e do espaço e, também, às ações de pesquisa.

\section{Referências bibliográficas}

BARDIN, L. Análise de conteúdo. 4. ed. Lisboa: Ed. 70, 2007.

BOAVIDA, A. M.; PONTE, J. P. Investigação colaborativa: potencialidades e problemas. In: GTI (Org.). Reflectir e investigar sobre a prática profissional. Lisboa: APM, 2002. p. 43-55.

BRASIL. Ministério da Educação (MEC). Secretaria de Educação Fundamental (SEF). Parâmetros curriculares nacionais: matemática (ensino de primeira a quarta série). Brasília: MEC/SEF, 1997.

CRESWELL, J. W. Projeto de pesquisa: métodos qualitativo, quantitativo e misto. 2. ed. Porto Alegre: Artmed, 2007.

CURI, E. A matemática e os professores polivalentes. São Paulo: Musa, 2005. 
CURI, E. Projeto Prova Brasil de Matemática: revelações possibilidades de avanços nos saberes de alunos de $4^{\mathrm{a}}$ série $/ 5^{\circ}$ ano e indicativos para formação de professores. Projeto de pesquisa aprovado no âmbito do edital de 2010 do Programa Observatório da Educação da Capes. São Paulo, 2010. [Não publicado].

CURI, E. Sistema de numeração decimal: uso cotidiano e aprendizagens escolares. In: CONFERÊNCIA INTERAMERICANA DE EDUCAÇÃO MATEMÁTICA (CIAEM), 13., 2011, Recife. Anais... Recife: Universidade Federal de Pernambuco, 2011.

CURI, E.; SANTOS, C. A. B. A compreensão dos resultados da prova Brasil de matemática para o $5^{\circ}$ ano do ensino fundamental e implicações para sala de aula: a contribuição de um grupo colaborativo. In: SEMINÁRIO DE INVESTIGAÇÃO EM EDUCAÇÃO MATEMÁTICA (SIEM), 22., Lisboa. Actas... Lisboa: Universidade de Lisboa, 2011a.

CURI, E.; SANTOS, C. A. B. Contribuições de avaliações externas à prática pedagógica do professor que ensina matemática para crianças de 6 a 10 anos no que se refere ao sistema de numeração decimal. In: ENCONTRO DE PROFESSORES DE MATEMÁTICA (ProfMat), 2011, Lisboa. Actas... Lisboa: Universidade de Lisboa, 2011b.

CURI, E.; SANTOS, C. A. B.; RABELO, M. M. Aprendizagens e dificuldades de alunos de $5^{\circ}$ ano com relação ao sistema de numeração decimal. Educação Matemática em Revista, Canoas, RS, [no prelo].

FIORENTINI, D. Pesquisar práticas colaborativas ou pesquisar colaborativamente? In: BORBA, M. C.; ARAÚJO, J. L. (Org.). Pesquisa qualitativa em educação matemática. Belo Horizonte: Autêntica, 2004. p. 47-76.

FIORENTINI, D. (Org.). Formação de professores de matemática: explorando novos caminhos com outros olhares. Campinas, SP: Mercado das Letras, 2003.

FIORENTINI, D.; NACARATO, A. M. (Org). Cultura, formação e desenvolvimento profissional de professores que ensinam matemática: investigando e teorizando a partir da prática. São Paulo: Musa, 2005.

FIORENTINI, D.; NACARATO, A. M.; PINTO, R. A. Saberes da experiência docente em matemática e educação continuada. Quadrante: Revista Teórica e de Investigação, Lisboa, Portugal, v. 8, p. 33-60, 1999.

LERNER, D.; SADOVSKY, P. O sistema de numeração: um problema didático. In: PARRA, C; SAIZ, I. Didática da Matemática: reflexões psicopedagógicas. Porto Alegre: Artmed, 1996. 
PARRA, C.; SAIZ, I. Didática da Matemática: reflexões psicopedagógicas. Porto Alegre: Artmed, 1996.

PASSOS, C. L. B.; NACARATO, A. M. et al. Desenvolvimento profissional do professor que ensina Matemática: uma meta-análise de estudos brasileiros. Quadrante: Revista Teórica e de Investigação, Lisboa, v. 15, n. 1-2, p. 193-219, 2006.

PONTE, J. P. Da formação ao desenvolvimento profissional. In: ENCONTRO DE PROFESSORES DE MATEMÁTICA (ProfMat), 1998, Lisboa: APM, 1998. p. 27-44.

PONTE, J. P. Investigar a nossa própria prática. In: GTI (Org.). Reflectir e investigar sobre a prática profissional. Lisboa: APM, 2002. p. 5-28.

RABELO, M. H. M. Questões envolvendo o sistema de numeração decimal: revelações da Prova Brasil e de alunos da rede pública. 2012. 111 f. Dissertação (Mestrado em Ensino de Ciências e Matemática) Universidade Cruzeiro do Sul, São Paulo, 2012.

RABELO, M. H. M.; CURI, E. Contribuições da Prova Brasil à pratica pedagógica do professor que ensina matemática para crianças de 6 a 10 anos no que se refere ao sistema de numeração decimal. In: ENCONTRO DE PRODUÇÃO DISCENTE EM EDUCAÇÃO MATEMÁTICA, 4., 2011, São Paulo. Anais... São Paulo: Pontifícia Universidade Católica, 2011.

SACRISTÁN, J. G. O currículo: uma reflexão sobre a prática. Porto Alegre: ArtMed, 2000.

SANTOS, C. A. B.; PEREIRA, J. F. F. Análise das respostas de professores ao questionário do SAEB/Prova Brasil. In: CONFERÊNCIA INTERAMERICANA DE EDUCAÇÃO MATEMÁTICA (CIAEM), 13., 2011, Recife. Anais... Recife: Universidade Federal de Pernambuco, 2011.

SARAIVA, M.; PONTE, J. P. O trabalho colaborativo e o desenvolvimento profissional do professor de Matemática. Quadrante, Lisboa, v. 12, n. 2, p. 25-52, 2003.

SHULMAN, L. Those who understand: knowledge growth in teaching. Educational Research, v. 15, n. 2, p. 4-14, 1986.

SILVA, S. D. Formação continuada na HTPC: refletindo sobre o ensino da Matemática nos anos iniciais do ensino fundamental. 2009. Dissertação (Mestrado) - Universidade Cruzeiro do Sul, São Paulo, 2009. 
SILVA, S. D. Formação continuada: o uso da calculadora e o sistema de numeração decimal. In: SEMINÁRIO DE HISTÓRIA E INVESTIGAÇÕES NAS AULAS DE MATEMÁTICA, 2010, Campinas. Anais... Campinas:

Faculdade de Educação, Unicamp, 2010.

TARDIF, M. Saberes docentes e formação profissional. Petrópolis, RJ:

Vozes, 2002.

TARDIF, M.; BORGES, C. Apresentação do dossiê "Os saberes dos docentes e sua formação". Educação e Sociedade, Campinas, v. 22, n. 74, abr. 2001.

VECE, J. P.; SILVA, S. D.; CURI, E. Investigações sobre o processo de aprendizagem dos alunos do $5^{\circ}$ ano do ensino fundamental a partir de questões do Saeb/Prova Brasil. In: SEMINÁRIO PROVA BRASIL DE MATEMÁTICA, 2011, São Paulo. Revelações e possibilidades de avanços nos saberes de alunos de $4^{a}$ série $/ 5^{\circ}$ ano e indicativos para formação de professores. São Paulo: Universidade Cruzeiro do Sul, 2011. [Não publicado].

Edda Curi, doutora em Educação Matemática pela Pontificia Universidade Católica de São Paulo (PUC-SP), é vice-coordenadora e docente do Programa de Mestrado Profissional em Ensino de Ciências e Matemática da Universidade Cruzeiro do Sul, São Paulo, São Paulo, Brasil. edda.curi@cruzeirodosul.edu.br

Recebido em 29 de agosto de 2012.

Aprovado em $1^{\circ}$ de março de 2013. 